\title{
Homilía
}

\section{La importancia de los mártires}

\author{
José María Tojeira \\ Provincial de la Compañía de Jesús \\ en Centroamérica
}

Según la palabra de Dios, los mártires son luces en la historia que muestran una razón para vivir. Por eso, desde el punto de vista cristiano, es indispensable recordarles. $Y$ como en todo martirio, hay en ellos un aspecto de anuncio y otro de denuncia.

Hoy, en este quinto aniversario, quisiera centrarme más en lo que tienen de anuncio los mártires, y en particular todos nuestros hermanos mártires salvadoreños. Desde los más conocidos hasta los menos conocidos. Desde el celebrador de la palabra anónimo del cantón más perdido de este país, acribillado por cargar la Biblia en sus manos, hasta Mons. Romero, camino de los altares. Ellos nos dan ejemplo de generosidad sin que la muerte y la amenaza fueran estorbo para su entrega al prójimo.

El salvadoreño actual, y especialmente si es cristiano, debe beber en las fuentes de su pasado reciente. Por supuesto, sin quedarse en el pasado. Si la guerra se debió en buena parte a la idolatría de la riqueza y a la rebelión contra las esclavitudes que esta riqueza imponía, el cristiano comprometido con su historia debe buscar una sociedad construida sobre el compartir más que sobre el poseer individualmente. Si durante la guerra se creó una cultura de la muerte que despreciaba los más elementales derechos de la persona, el que cree hoy en Jesucristo debe ser un acérrimo defensor de la vida. Si dentro de la cultura de la muerte se llegó a asesinar en el Mozote a más de cien niños con una edad promedio de seis años, hoy es indispensable ver los problemas de la niñez y trabajar en su solución. Vemos el pasado, pero para construir mejor nuestro futuro. 
$Y$ debe ver al futuro teniendo en cuenta esos valores de generosidad, audacia, coherencia y compromiso que nos recuerdan los mártires como semilla actualizada del gran martirio de Jesús.

El Salvador necesita personas generosas. Que sepan dar su tiempo al prójimo y a sus problemas. Que estén atentos a los justos reclamos de los empobrecidos de nuestra sociedad. Que visiten a los enfermos y a los encarcelados, que partan su pan con el hambriento, que pateen el campo con quienes lo sudan, que traten de construir una sociedad realmente fraterna.

Personas audaces, con fuerza para pensar un futuro distinto al actual. Imponiendo valores que vayan más allá de la sesuda, sensata y artificial verborrea de quienes nos dicen que todo está bien, o simplemente mejor, mientras en la calle se dispara contra los buseros de San Miguel en un problema que debía arreglarse dialogando. Audacia para reformar este sistema judicial no solamente con problemas de corrupción, sino ineficaz a la hora de tratar con igualdad a las mayorías pobres y a las minorias pudientes (sigue siendo igual de cierta que en el pasado aquella frase de Mons. Romero que decía que la justicia salvadoreña es como la culebra, sólo le muerde el pie al que camina descal$z o)$.

Audaces para decir la verdad a los políticos, a los jueces, a los poderosos y a los escuadroneros. Resistiendo la farsa de aquellos que se quieren mostrar como los primeros de este país, pero son incapaces de rendir homenaje público a Mons. Romero. Enfrentando a quienes nos hablan de honestidad día y noche, pero se mueven hábilmente en un ambiente de corrupción y se niegan a reformar esas leyes que al final de sus robos o de sus delitos les permiten decir que no hay pruebas.

Cómo recordar a Mons. Romero o a Ellacuría, por mencionar solamente nombres simbólicos de muchos martirios, sin contagiarnos de audacia cristiana. Estas recias personalidades pusieron nerviosos a muchos de los que viven prepocupados prioritariamente por su seguridad, por su poder o por su dinero. Pero hoy, esta reciedumbre personal sólo podemos contemplarla como signo de una intensa vida interior anclada en Jesucristo.

El Salvador necesita personas coherentes. Que si piensan que el pueblo salvadoreño es el principal artífice de la paz, honren y defiendan al pueblo salvadoreño. Que si están convencidos que los mártires, los pacíficos asesinados por su compromiso con la paz, expresan lo mejor de este pueblo, celebren a las víctimas de las masacres del Mozote, del Sumpul, de Las Hojas, del Calabozo, de tantos otros lugares, instituyendo uno a varios días al año a los que les demos tanta o más importancia que a las fiestas oficiales. Solo el recuerdo fiel de las víctimas nos libera 


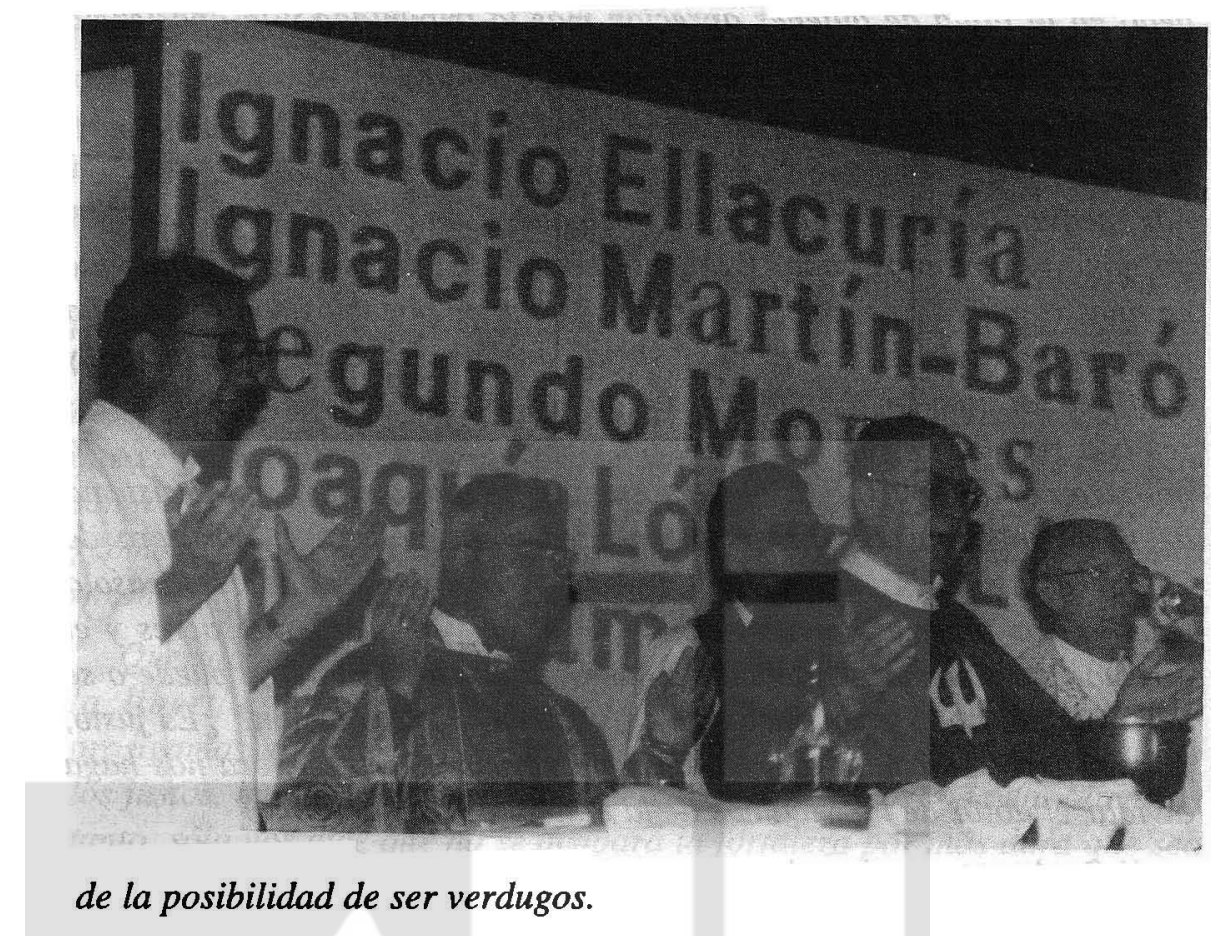

Coherencia en política, coherencia en la sociedad civil, coherencia a la hora de construir un futuro pacífico. Si nuestros mártires jugaron un papel protagónico en la construcción de la paz, cómo es posible que surjan instituciones en pro de la paz que tienen como asesores a los que dieron la orden de ejecutar a los protagonistas de la paz.

Coherencia en nuestra fe cristiana. Perdonar sin ocultar la verdad. Qué fácil es simplificar este tema y qué difícil es vivirlo a fondo. Con frecuencia, a los jesuitas nos preguntan si hemos perdonado a quienes mataron a nuestros hermanos. Claro que lo hemos hecho. $Y$ hemos visto que entre la gente sencilla del ejército que participó en la matanza de nuestros compañeros, el perdón ha dado buenos resultados. Se han arrepentido, han dicho la verdad y han crecido en coherencia con su arrepentimiento. Tanto por ellos, como por los que no se han arrepentido, algunos de nosotros seríamos capaces de dar la vida, especialmente si alguien tratara de arrebatársela violentamente.

Pero eso es una cosa y otra es que algunos de los que mataron a los inocentes no sólo nos digan que aquí no ha pasado nada, sino que traten de presentarse como los principales autores de la paz. Está bueno que trabajen por la paz, pero que tengan la valentía de san Pablo que se reconocía a si mismo como antiguo perseguidor de la Iglesia, precisamente para resaltar la obra de Dios en él. Mientras tanto, para ayudarlos, y aun perdonándolos de corazón, será necesario seguir poniendo el 
dedo en la llaga de quienes aprecian más la impunidad y la apariencia que la verdad que purifica.

No habrá coherencia cristiana si no somos capaces de luchar contra las causas que generaron la guerra y que permanecen, algunas en menor medida, presentes en nuestra sociedad. Como tampoco la habrá si no nos preguntamos cada día cómo aliviar el dolor de tanta gente que en nuestro país sufre, no sólo por causas que no podemos controlar, sino también por una estructuración social que genera deshumanización y conflicto en muchos de nuestros hermanos. Siguen apareciendo cadáveres con señales de tortura, se atenta y se mata a dirigentes políticos, la pobreza continúa como la plaga principal del país, el deficiente sistema de salud margina o simplemente golpea a los pobres, el basurero de Santa Tecla se derrumba y sepulta vivas a personas que no tenían casa o trabajo, los presos se matan en la cárcel en verdaderas masacres y el director del sistema penitenciario continúa en su puesto. ¿Se puede o se debe olvidar todo esto sin darle seguimiento a su solución? ¿Es justo, por no decir cristiano, que la siguiente noticia estremecedora nos haga olvidar el dolor de las víctimas de la noticia del día anterior?

$Y$ finalmente testimonio. Si tenemos inteligencia, si tenemos capacidad de trato, si destacamos por nuestra habilidad política, si somos dueños de poder o de riqueza, cómo decir que somos cristianos sin compartir lo que somos y tenemos. Nuestros mártires, todos los mártires, conocidos o anónimos de El Salvador, dieron con su vida el testimonio definitivo de ser fieles a lo que pensaban. Su recuerdo es ahora motor, impulso y exigencia para nuestro testimonio personal. No se puede vivir con lujo y ostentación en un país donde hay todavía demasiada pobreza. No se puede vivir despreocupadamente donde tantas personas tienen preocupaciones de vida o muerte. Se impone un modo de vida, personal, social y político en el que la solidaridad, la austeridad y el diálogo sean las constantes de la acción. Ellacuría le llamaba a ésto la civilización de la pobreza. Y es que el testimonio personal debe cuajar en estructuras de convivencia humana y responder así a la vida de este país.

Generosidad, audacia, coherencia y testimonio, debemos vivirlas en un contexto duro, pero no desesperado. El Salvador está en un buen momento. Hay paz, hay mayor capacidad de diálogo, hay más libertad. Hay mucho más interés en que se combata la corrupción, la delincuencia, el narcotráfico, en que se destierren para siempre las prácticas escuadroneras, reducidas, pero vivas todavía. El salvadoreño en general tiene mejores sentimientos y sabe mejor lo que necesita. Los empobrecidos se organizan, discuten y buscan sus derechos con ahinco. El tiempo es bueno, aunque muchos no lo estemos aprovechando tan bien como debiéramos. El evangelio y sus testigos martiriales nos invitan al com- 
promiso ciudadano, a no dejar pasar las cosas, a crecer, desde cualquier plataforma en la que nos encontremos. Crecer en coherencia personal, en palabra pública, en presión política, en organización solidaria con todas las personas de buena voluntad que nos rodean y que son muchas.

El camino hacia la paz es largo y según vamos avanzando en él percibimos con mayor claridad la enorme distancia que nos queda por recorrer. No tiene sentido, ni mucho menos valor cristiano, el caer en el desencanto porque, ahora que hemos avanzado algo, vemos que nos queda por caminar más de lo que suponíamos. Hemos avanzado, hay sangre generosa en los cimientos de esta lucha y de este peregrinar, ¿cómo vamos a traicionar este pasado generoso por la simple y banal razón de que la meta no está todavía al alcance de la mano?

Queridos hermanos en Cristo y en la lucha pacífica por la dignidad y la libertad humana: dejemos atrás cansancios y desalientos y prosigamos el camino. La sangre martirial garantiza el triunfo final de los justos, que no sabemos si está cercano o muy lejos todavía. Mientras tanto, sólo nos dice que no se acabará la fortaleza por más dura que sea la lucha. Para la locura de la cruz es perfectamente cierta aquella frase de don Quijote a Sancho, después de fracasar en su batalla con los molinos de viento: "Bien podrán los encantadores quitarnos la ventura, pero el esfuerzo y el ánimo será imposible".

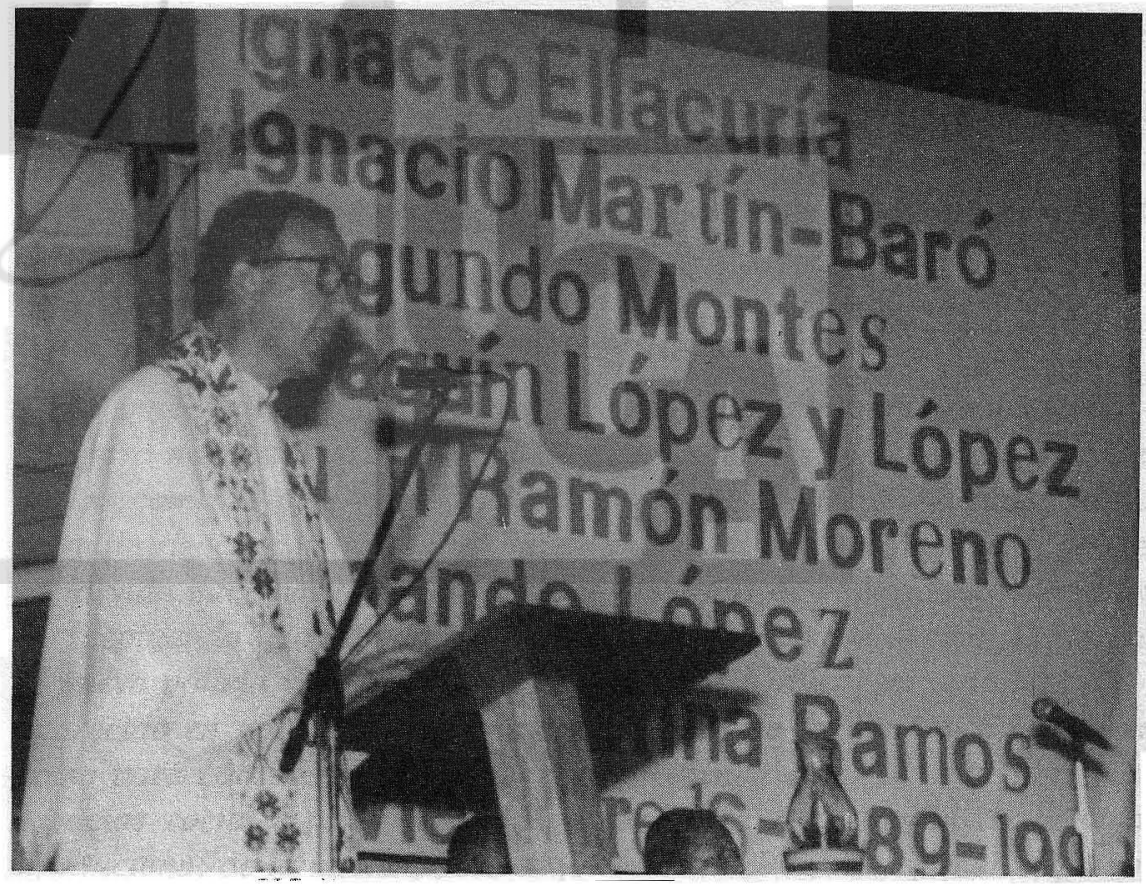


Acerquémonos con fe a este maná de la Eucaristia, donde Jesús se nos entrega como fuerza generosa y combativa, y tengamos la seguridad de que el Señor está siempre entre nosotros, fuerza en nuestro camino, dando sentido a nuestros éxitos y fracasos, en la medida en que nuestras luchas se ajusten a los valores del evangelio. Que así sea.

San Salvador, 16 de noviembre de 1994. 